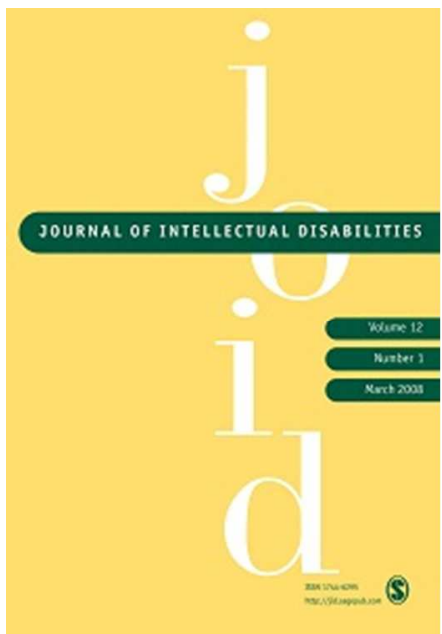

\title{
Sleep hygiene education and children with developmental disabilities: findings from a co-design study.
}

\begin{tabular}{|r|l|}
\hline Journal: & Journal of Intellectual Disabilities \\
\hline Manuscript ID & JID-18-0025 \\
\hline Manuscript Type: & Original Research \\
\hline Keywords: & $\begin{array}{l}\text { children, developmental disabilities, sleep hygiene education, experience } \\
\text { based co-design, programme theory }\end{array}$ \\
\hline & $\begin{array}{l}\text { This qualitative study develops a programme theory demonstrating the } \\
\text { complexity embedded in sleep hygiene education (SHE) as an intervention } \\
\text { to improve sleep problems in children with developmental disabilities } \\
\text { (DD). In co-design workshops, eight parents and six sleep practitioners } \\
\text { deliberated discussion themes developed from a thematic analysis of } \\
\text { exploratory study data, guided by a 'trigger' podcast illuminating parents' } \\
\text { narratives of SHE. A SHE tool underpinned by programme theory } \\
\text { abstracted to mid-range theories of change was developed. Analytical } \\
\text { themes were proposed: the need to enhance the legitimation of children's } \\
\text { sleep problems and consider the nature of customisation, knowledge } \\
\text { sharing, health expectation and impact of sleep service rationing and } \\
\text { gaming strategies on implementation success. Policy and practice } \\
\text { implications include a need to raise the public profile of children's sleep } \\
\text { problems and promote parental involvement in intervention } \\
\text { implementation. Further research is needed to test out this theory-driven } \\
\text { framework for evaluating SHE. }\end{array}$ \\
\hline Abstractions
\end{tabular}




\section{fJournal of Intellectual Disabilities Publication.}

\section{Introduction}

Children with developmental disabilities (DD) (Table 1) commonly experience severe and persistent sleep problems (Bonuck and Grant, 2012; Sutton, 2011; Tietze et al., 2012), which are associated with negative outcomes for the child (e.g., daytime challenging behaviour and impaired educational performance) (Beresford et al., 2012; Galland and Mitchell, 2010) and the family (e.g., increased stress and relationship difficulties) (Family Fund, 2013). To ensure appropriate treatments are advocated, current evidence suggests that sleep problems should be assessed to eliminate physiological causes, and to identify those which are behavioural in origin (linked to parental management issues) (Malow et al., 2013; McDaid and Sloper, 2009). An essential first intervention for behavioural sleep problems is sleep hygiene education (SHE) (National Institute for Health and Care Excellence, 2013; Vriend et al., 2011) which advises parents on creating optimal sleeping conditions for their child and exposes them to "activities and cues that prepare them for and promote appropriately timed and effective sleep" (Jan et al., 2008, p.1344) (e.g., creating consistent bedtime routines, avoiding caffeine and encouraging daytime exercise).

[Table 1 to be inserted here] Operational definition of developmental disabilities (DD). (This has been specifically developed for the purposes of this study and encompasses a variety of neurological conditions). 


\section{Developing a theoretical understanding of SHE.}

SHE can be viewed as a complex intervention which has multiple interacting components such as behaviours, organisational methods and settings. It is often difficult to identify the active ingredients which make complex interventions work, however, it is important that services engage in systematic evaluations so that intervention effectiveness can be repeated (Medical Research Council, 2000, 2008). It is common for individuals working in health or social care organisations to have a poor understanding of how interventions bring about change, and they may engage in un-informed implementation of ineffective practices for years (Funnell and Rogers, 2011). Indeed, SHE is currently supported by theories based on popular wisdom (Galland and Mitchell, 2010, Jan et al., 2008) and it is routinely implemented without explicit explanation of what SHE programme activities are supposed to achieve. Notwithstanding, in the existing cost-conscious climate of prudent healthcare (Bradley and Willson, 2014) it is essential that practitioners deliver evidence-based, transparent care which is relevant to individual need.

The Medical Research Council (MRC) framework for evaluating complex interventions (2000, 2008) advises that intervention evaluations should be underpinned by an evidence review that is also augmented by additional primary research with stakeholders to build theoretical understanding. Accordingly, an earlier scoping review (Author 1 [ ] ) identified mixed evidence underpinning SHE content and a limited theoretical base. Review findings informed the development of a preliminary, evidence based SHE tool for children with DD and design of a subsequent exploratory investigation into the experiences of parents and sleep practitioners (from health and social care organisations) regarding SHE. A thematic analysis (Braun and Clarke, 2006) of exploratory study data identified parent and sleep practitioner themes which were synthesised with review findings and summarised as six overarching themes. These 
represented pre-implementation challenges and achievement of intermediate and ultimate outcomes culminating in improved sleep and quality of life (Table 2).

The current, co-design study aimed to build on collated evidence, co-create and develop the preliminary SHE tool and further build a theoretical understanding of SHE by constructing a programme theory (Astbury and Leeuw, 2010; Chen, 2015). Programme theory comprises a 'theory of change' which describes the core processes by which change occurs and a 'theory of action' which explores what an intervention does to activate the outcomes espoused in a theory of change (Funnell and Rogers, 2011). Programme theory development provides a fresh consideration of the familiar intervention of SHE and helps to clarify a distinction between implementation failure (the intervention is performed incorrectly), or theory failure (intervention performed correctly, but was still unsuccessful) (Funnell and Rogers, 2011) to ensure SHE can be replicated effectively and evaluated reliably in a theory driven manner.

Co-design study findings advance the knowledge base supporting SHE in the following ways:

1. Presents an evidenced based SHE tool for children with DD.

2. Develops a systematic understanding about what SHE does, how it is delivered and how it is supposed to work to improve sleep (programme theory).

3. Links programme theory with mid-range theories of change which increases transferability.

4. Develops explanatory analytical themes which demonstrate SHE complexity. 
[Table 2 to be inserted here] Six co-design study discussion themes.

\section{Method.}

\section{Research design and overview of the study.}

A participatory methodology approach was adopted. This champions collaborative research 'with' participants who are viewed as equal research partners, rather than as subjects who are being researched and incorporates an action agenda (Creswell, 2007; Reason and Bradbury, 2001). The Experience Based Co-Design (EBCD) (The King's Fund, 2014) participatory method was drawn upon. This is primarily a public and professional involvement, service improvement tool that recommends a series of activities to plan for change with stakeholders (Figure 1). The standard EBCD design can be adapted to suit different settings and budgets (Donetto et al., 2014; Locock et al., 2014), and in the present study, it was modified as follows (Figure 2): Stages 1 and 2 were addressed by the Community Learning Disability Nursing experience of [Author 1] and the findings of the earlier scoping review and exploratory study which produced six overarching discussion themes (Table 2) to flexibly guide co-design group debate. The next step of producing a service user film underwent a novel adaptation: a 'trigger' podcast was developed from the audio recorded exploratory parent interviews using an Audacity software package. The member checked, preliminary parent themes from the exploratory study, were portrayed by selecting exemplar parent voice extracts and the final podcast was reviewed by the research team for accurate representation. Instead of using visual imagery, it was felt that the audio channel of communication could rouse the creation of mental images in listener's minds (Rodero, 2012), stimulating a personal connection with emotional touchpoints and rich 
discussion. Stage 4 was omitted as the earlier exploratory study involved a second practitioner focus group, in which practitioners gave their approval to share validated themes with parents. The next three EBCD steps were condensed into a parent only, and two joint parent and sleep practitioner workshops in which the podcast was broadcast and co-designers co-created a SHE tool and iteratively developed a programme theory. Finally, the celebration event was replaced with the dissemination of research findings to stakeholders through the conduit of a lay summary.

[Figure 1 to be inserted here] Experience based co-design (King's Fund, 2014).

[Figure 2 to be inserted here] Overview of adapted co-design method.

\section{Ethics}

Institutional [IDENTIFIER TO BE INSERTED FOLLOWING REVIEW] ethical approval was obtained. The study as framed as a service evaluation from the perspective of NHS ethical reviewers. It was not carried out on NHS premises and did not recruit parents or practitioners through the NHS. Accordingly, confirmation was received from the Health Research Authority the $10^{\text {th }}$ April 2015 that Research Ethics Committee (REC) approval was not required. All participants gave informed written consent to participate in the co-design events.

\section{Participants.}

A purposive sample of 21 parents and eight sleep practitioners were recruited from social care teams and UK voluntary organisations supporting families of children with DD. Parents were 
invited to participate if (i) they had a child with DD aged 3-18 years with experience of sleep problems, and (ii) had some experience of SHE to treat their child's sleep problems.

Practitioners were invited to take part if (i) they had at least six months experience of supporting families of children with DD aged 3-18 years with sleep problems, and (ii) were experienced in the use of SHE. Each event ran for two hours and was held at parent-friendly voluntary organisation meeting rooms. Participant, event facilitator and venue availability were collected to set dates and times for the three co-design events. A total of eight parents and six sleep practitioners took part (Table $3 \& 4$ ).

\section{[Table 3 to be inserted here] Parent participant characteristics..}

\section{[Table 4 to be inserted here] Sleep practitioner participant characteristics.}

\section{Procedure}

Co-designers were presented at the start of each event with five specific aims: 1) To gather views on how sleep practitioners and parents should work together to ensure families of children with DD receive effective sleep advice[1]\# and support with sleep problems. 2) To focus on what a parent's journey toward receiving professionally supported sleep advice should look like. 3) To really understand what makes effective sleep advice and support work. 4) To think systematically about what sleep practitioners need to do when they advise and support families with sleep problems. 5) To explore parent/sleep practitioners' views on the acceptability of sleep advice content. In the first co-design event, parents were shown the six discussion themes (Table 2) and emerging ideas around process and contextual factors from the exploratory study identified by the research team, and invited to confirm, challenge or add to them. As part of the iterative process, they were asked to discuss what actions needed to happen on a parent, professional, organisational and policy level to improve how families were supported with sleep. 


\begin{abstract}
Parents were then invited to listen to the podcast, reflect on and share any new insights which its broadcast may have triggered.
\end{abstract}

To draw together emerging ideas from parent co-designers and enable effective facilitation at the second event (parent and practitioner) a wall sized representation of the six discussion themes and emerging constructions was prepared, based on an adapted version of the person centred planning tool: the Planning Alternative Futures with Hope 'PATH' (Pearpoint, O'Brien and Forest, 1998). This is a planning style used with individuals which helps them understand complex situations and take control over change (Sanderson and Lewis, 2012). It was felt this mirrored a participatory approach and served as a constant visual reminder of workshop aims to keep data collection focused. Co-designers were firstly asked to consider the ultimate goal of SHE 'Quality of life improves for the family' and asked to record on post-it notes how success would make them feel which were placed on the PATH model. The PATH planning approach then brings participants back to the present and requires them to examine what life is like now. As indicated by Sanderson and Lewis (2012), this creates a tension between the existing problem and ultimate goals, and motivates the group to plan for change. Accordingly, codesigners were asked to consider discussion theme 1 'Parents and practitioners have a shared understanding of what a sleep problem is' which reflected the start of a family's journey towards improved sleep. Co-designers' constructions or priorities for sleep service improvement were recorded on the wall sized PATH model under theme 1's column and subsequent discussion themes were deliberated in turn and responses recorded. The podcast was also played to the group and their reactions recorded under the appropriate discussion theme columns. 
In the final parent and practitioner event, co-designers were again referred to the developing PATH model and asked to deliberate remaining discussion themes and revisit any constructions requiring further clarification. Participants were then presented with six SHE advice areas and related components identified from the earlier scoping review: sleep timing, bedtime routines, communication adaptations, environment, behaviour management and physiological factors. As a group they were asked to report on their views regarding the acceptability of SHE advice and how implementation should be supported. This concluded the co-design events.

\section{Data analysis}

All events were audio taped and video recorded for the purposes of verbatim transcription and data were thematically analysed (Braun and Clarke, 2006) in relation to the six discussion themes (Table 2). Data were coded to identify repeated debates of topics related to each discussion area. Co-designer's comments from each event which indicated agreement or disagreement with existing findings and any new constructions or priorities for sleep service improvement were sequentially recorded separately on the developing PATH model. Trustworthiness was demonstrated through member checking (Burnard et al., 2008) of findings by co-designers, triangulation through adopting multiple data collection methods, and keeping a clear evidence trail throughout the co-design process. Scoping review, exploratory and codesign study findings were synthesised to iteratively develop a SHE tool, programme theory and explanatory logic model which were scrutinised by the research team. Analytical correlations were also made with mid-range (research based) and novel theories of change to demonstrate the nature of complexity embedded in a SHE intervention for children with DD.

\section{Findings.}




\section{SHE tool development.}

A SHE tool incorporating six advice areas and 45 individual components for sleep practitioners to select from, was developed from synthesising scoping review and co-design study findings (Table 5). Advice components were included if they were supported by a minimum of two scoping review citations or one citation plus additional research evidence or co-designer agreement, to ensure tool validity.

[Table 5 to be inserted here] SHE tool for children with DD.

\section{Programme theory development.}

This study developed a programme theory to underpin the SHE tool. This was visually represented as an outcomes chain logic model (Figure 3), which is circular to emphasise the holistic approach and the cyclical rather than linear process of the intervention. The theory of change is illustrated by the blue boxes in the diagram's centre, depicting each of the intervention's outcomes. The lightest blue boxes represent the immediate outcomes, mid-blue boxes represent intermediate outcomes and the final two darkest blue boxes show the ultimate outcomes of SHE. Outcomes are graded (focused and scoped) in terms of how much they can be directly attributed to the intervention, to ensure programme results are not under or overclaimed and intervention complexity is not overlooked.

Typically, parents and practitioners begin at the 'Parents and practitioners have a shared understanding of what a sleep problem is' outcome and move in a clockwise direction achieving 
intermediate and ultimate outcomes (as represented by the black arrows- intended progression of outcomes). The mechanisms by which each outcome is achieved are explained in the theory of action (available by contacting authors) represented in the first encompassing purple ring, which incorporates: success criteria, programme factors, non-programme factors, activities processes and principles, resources and inputs (financial and human) outputs and throughputs (Funnell and Rogers, 2011). However, parents may backtrack to previously attained outcomes or exit the intervention at various time-points and after a period of time re-join at the stage of 'Parents and practitioners have a shared understanding of what a sleep problem is'. To represent this, red arrows show how outcomes are sometimes not achieved as originally intended, due to contextual factors (programme and non-programme factors) and the intervention fails or takes longer to work.

[Figure 3 to be inserted here] SHE programme theory- outcomes chain logic model.

Emerging conceptualisations with mid-range theories of change - Self-efficacy, Empowerment, Normalisation and the Trans-theoretical model (TTM) of change- are depicted in the green ring. Novel analytical themes -legitimation, customistation, knowledge sharing, health expectation and rationing and gaming- are denoted in the outer yellow ring. Both rings encapsulate the theory of change and action to show how they have relevance across all outcomes.

\section{Application of mid-range theories of change.}

\section{Self-efficacy theory.}

Findings showed how parents' ability to both recognise children's sleep problems and engage with SHE, was affected by the attitudes and support of others. This links with self-efficacy theory 
(Bandura, 1977; 1997) which holds that people with a strong sense of self-efficacy frequently achieve success, whereas those who doubt their capabilities yield when faced with challenges. In the 'Parents and practitioners have a shared understanding of what a sleep problem is' outcome, the contextual factor was identified of parents' partners and relatives needing to concur on sleep problem existence. Co-designers acknowledged how wider family members sometimes adopted stoic attitudes towards children's sleep difficulties, making it harder for parents to publicly acknowledge them. This chimes with the self-efficacy building strategy of 'social persuasion' whereby individuals who receive encouragement often achieve positive outcomes:

"It took some convincing with my husband, you know that we had a problem in the first place because, in his parent's generation, it goes under the carpet you forget about it, it doesn't exist, well I'm sorry but it does." (Parent).

In the 'Regularity and quality of child's sleep improves' outcome, links were made with other main strategies which build self-efficacy. The activity of motivating parents to measure improvements by completing sleep outcome measures chimes with 'mastery experiences' which holds that success is achieved through perseverance. Also, the contextual factor of practitioners acknowledging the readiness and capacity of parents to engage with SHE advice, relates to the strategy of 'modifying individual's perceptions of their physical and emotional states'.

\section{Empowerment theory.}

Findings showed how parents wanted to be empowered to identify their children's sleep problems, access sleep services, and take an active role in assessing sleep problem causes. This espouses the tenants of empowerment theory which encompasses self-determination and participation, and posits that problems are best addressed by those experiencing them (Perkins 11 
and Zimmerman, 1995). In the 'Parents and practitioners have a shared understanding of what a sleep problem is' outcome, the screening activity was identified of parents having the option of referring to a sleep checklist in their Personal Child Health Record (PCHR) or hand held 'Red Book'. Parents posited they should be well informed of sleep expectations and be able to promptly identify sleep problems independently using the familiar PCHR. This demonstrated parents need to be active participants, taking ownership of their child's health rather than passive or powerless recipients of care:

"More pages within the red book to ask you or make you do your own analysis of is your child up to scratch?" (Parent)

The outcome of 'Sleep services are well publicised and accessible for parents' included activities which required sleep services to actively publicise themselves via the internet, posters and leaflets. Co-designers reported that sleep teams were often poorly advertised, creating an unnecessary barrier for parents who were motivated to seek support. Parents wanted to be empowered to independently source professional sleep help, which could be facilitated by sleep services raising their public profile:

"We need more promotion that there is help available."(Parent).

\section{Normalisation theory.}

Findings showed how parents expressed a need for 'normalcy' when addressing their children's sleep problems and desire not to feel different from other parents of typically developing children. This chimes with the tenants of normalisation theory (Gilbert, 2004; Wolfensberger and Tullman, 1982), which devalues difference and regards it as deviant, causing stigmatisation and social exclusion. In the outcome 'Parents and practitioners have a shared understanding of what 
a sleep problem is', the success criteria of ensuring all children were screened for sleep problems was identified. Co-designers agreed sleep practitioners should ask ALL parents about sleep whether their child had a DD or not. It was important for parents not to feel different from others when they embarked on the process of accepting there might be a problem with the way their child slept:

"It's got to be the norm(..) you don't feel like you are being singled out especially" (Parent).

In the outcome 'sleep services are well publicised and accessible for parents', the success criteria of parents sourcing sleep help through a generic sleep service was posited which links with a desire for sameness and normalisation principles. Parents described how it would be easier to approach a mainstream rather than specialist service as a first point of call for sleep help.

"Why does it need to be different? (..) Kids could just have a sleep issue, that could be their only issue I don't understand why you have to have separate."(Parent)

However, some co-designers disagreed with mainstreaming sleep service provision arguing that the specific needs of children with DD could be overlooked:

"It's the worse thing for parents I think would be going to a generalist sleep advisor and then having explain what the condition the child has ." (Parent)

\section{Stages of change theory (Transtheoretical model).}


Findings indicated that parents often go through distinct stages of change in their journey towards improved sleep, which broadly links to the transtheoretical model (TTM) of change (Prochaska and DiClemente, 1983; Prochaska and Velicer, 1997). This model centres on the principle that behaviour change is temporal and structured firstly by behavioural intention (thinking and planning for change), action, maintenance (behaviours sustained for six months) and termination (fully established behaviours).

Outcomes of 'Parents and practitioners improve their understanding of the sleep problem' and 'Regularity and quality of child's sleep improves' link to the action stage whereby parents actively engage with sleep problem assessment and making changes to sleep hygiene practices.

"After the assessment we have a specific session, we have it all out on a piece of paper yer, draw it all out (..) we want them to try and put it together like a jigsaw."

(Practitioner)

Progression to the outcome of 'Quality of life improves for the family' also abstracts to the maintenance stage where sleep improvements are sustained and the family experiences positive follow-on effects. This outcome incorporates the success criteria which highlights how parents need to feel supported to maintain progress via parent support groups.

"Parents need to know that there is this group, this group that and the other out there just so they can go "arggh!". That is really important." (Parent)

\section{Application of novel analytical themes.}

\section{Legitmation}


Constructions throughout the programme theory demonstrated stakeholders' perceptions of how children's sleep problems were under-valued and viewed as a private parenting issue by parents, practitioners, policy makers and wider society. It is posited that increasing the legitimacy of sleep problems is a foundation upon which SHE implementation needs to be based. For example, in the outcome 'Parents and practitioners have a shared understanding of what a sleep problem is', contextual factors of parents stoically coping with sleep problems and struggling to give precedence to sleep against competing health issues, demonstrate the influence of legitimacy on help seeking behaviours:

"It's not always going to be the first thing on your mind when you are trying to battle for lots of other things." (Parent)

To address this, co-designers made recommendations to legitimise sleep problems in the minds of parents, practitioners and wider society through increasing the public conversation about sleep and running national sleep screening initiatives and media campaigns to promote understanding. Co-designers also showed how they also perceived funders currently poorly prioritised sleep problems in children with DD, across all outcomes. This was linked to a lack of legitimacy afforded to the issue of children's sleep. Stakeholders reflected this in their requests for better financial resourcing of sleep teams to meet service need, provide continuity of parental support, produce comprehensive sleep assessments and champion parent support groups.

"I have tried to get him some help and nobody has ever mentioned any services (..)A lot of services always tell you they've got no money, it's not your fault is it?" (Parent).

\section{Customisation}


Findings make explicit the need to customise SHE advice according to assessed need, rather than giving poorly informed or standardised advice. It is posited that if parents perceive advice is tailored, they will feel motivated to follow it which positively impacts on implementation success. Customisation is defined within the broader context of healthcare as a shift away from standardisation to being responsive to the individual needs of patients/service users (deBlok et al .,2012; Minvielle et al., 2014). The notion of customisation is linked throughout the outcome of 'Parents and practitioners improve their understanding of the sleep problem'. Activities such as sleep practitioners performing multiple assessment sessions, at the child's home, at bedtime and involving other members of the multidisciplinary team and partner organisations in the sleep assessment show how SHE should be carefully considered and personalised to family need.

“Sometimes there's not enough information gained before things are put into practice that might not actually be right for that family." (Parent)

In the 'Parents and practitioners develop a safe and supportive relationship' outcome, the success criteria of 'Parents should receive the amount of support they need throughout their contact with sleep services' also demonstrates the impact of customisation in successful SHE implementation. Co-designers reported how sleep services sometimes fell short of parent's expectations in terms of frequency and duration of support:

"I didn't see her as many times as I would have liked to (..) I'm trying to get her back."(Parent)

\section{Knowledge sharing}

Findings make explicit the nature of knowledge sharing within SHE, which is defined as a twoway knowledge exchange between care providers and recipients of care that increases patient 
involvement and enhances positive outcomes (Davis and Meltzer, 2007; Tobiano et al., 2016).Co-designers made the recommendation of employing a paid parent buddy to share their knowledge with parents in the 'Regularity and quality of child's sleep improves' outcome. However, one practitioner questioned the acceptability of this, indicating how the role could be perceived as threatening:

"Would it not be an idea to have parent experts? Paid parents? (..)Frankly who has experience, who has actually been paid to do that. My point is they never give it the value that is deserves."(Parent)

“I still think that to pay for someone to mediate shouldn't that money be better spent training professionals on how to build that relationship and how to behave?" (Practitioner )

Knowledge exchange processes that focused on the responsibilities of sleep practitioners to freely share their expertise with parents were also identified in the ultimate outcome of improving children's sleep. For example, the process of delivering psycho-education to rationalise SHE advice was suggested by practitioners as a mechanism that could help support implementation; although parent co-designers did not report any first-hand experience of receiving this.

"I think just knowing(..) just finding out the reasons behind something can just put yourself at ease then, okay it doesn't get rid of the problem, but it puts yourself at ease then and you can start building on that." (Practitioner)

\section{Health expectation}


Findings demonstrate the added complexity of health expectation which holds that parents need to feel hopeful that their child's sleep can improve. Janzen et al. (2005) define a health expectation as a prediction relating to the effects of health behaviours on the psychological status of the body and suggest that expectations are highly important to the experience of health and health care. Data showed how low health expectations can impact on sleep problem recognition and when practitioners began with a negative outlook this invoked feelings of hopelessness in parents at the start of their SHE journey:

'With the GPs it was 'it's just the way he was' and I don't like that attitude it's just the way he was" (Parent)

Data also indicated how it is important to maintain parents' hope that sleep can improve during SHE implementation and that practitioners need to adopt an enduring reassuring attitude, to encourage parent's conviction in their abilities to effect change:

"She did it very positive (..) it kept him [son] hoping (Parent)

\section{Rationing and gaming}

Findings make explicit how the adoption of rationing and gaming strategies by sleep teams can affect implementation success. Such strategies are often employed by organisations when they change their behaviour to affect the results they report, as these will be used to control them (Bevan and Hood; 2006). It is posited that health (and social service) sleep teams reduce the accessibility of their service, to deter excessive referrals and keep waiting times or referral to treatment times within acceptable targets. In the 'Sleep services are well publicised and accessible for parents' outcome, it was recommended that sleep teams offer an open access, fully inclusive service for children aged 0-18, with any DD and with a broad geographical coverage. Co-designers suggested this in response to experiences of restrictive and complex 
entry processes to sleep teams, which had a negative impact on families trying to source support.

"Some families seem to fall through the net as well they don't fit this criteria." (Practitioner)

\section{Discussion}

The findings from this study enhance our understanding of how SHE is expected to work to improve sleep in children with DD. Abstracting programme theory to evidence based theories of change demonstrated how the intervention offers plausible solutions to sleep problems. The process encouraged critical reflection of programme theory; for example making analytical links with self-efficacy theory highlighted the potential for exploring in greater depth, strategies for building parent's self-efficacy and incorporating them into the intervention. In addition, making links with normalisation theory strengthened rationale for constructions presented. For example, it was posited that parents were often fearful of accessing specialist sleep services and stepping into disabled services, which was associated with a notion that difference was undesirable and something to be anxious about. Similar findings were shown in studies by Vogel and Wade (2009) and Dempster, Wildman and Keating (2013), which showed the need to consider stigma in service design, to ensure those who needed advice were supported to access it in a timely manner. Co-designers suggested a generic sleep service entry point for SHE to normalise seeking sleep help, however, some argued that generic practitioners may overlook the child's individual disability needs which links with established criticisms of normalisation that 
emphasise its denial of difference and value of conformity (Culham and Nind, 2003; Gilbert, 2004).

There were however, limitations in the application of mid -range theories of change. For example, applying the tenets of empowerment theory to all parents was problematic, as it could not be assumed everyone had the desire or capacity to play an active role in addressing their children's sleep problems. Programme theory accounted for this complexity by acknowledging how parents may not have the time, strength or literacy to engage and how practitioners needed to accommodate these contextual factors. In addition, whilst abstraction to the TTM of change was useful to help describe the different stages at which parents enter and move through a SHE programme, it was difficult to neatly match each outcome with each change stage because in reality parents and practitioners varied in their time spent achieving each outcome. This reflects a popular criticism of the TTM which argues that the categorisation of change into a series of distinct stages rather than a continuous process can be unrealistic (Armitage, 2009; Nigg et al., 2011). Therefore, whilst the process of making analytical links with mid-range theories encouraged critical reflection of programme theory, applicability issues meant they were viewed as heuristic devices rather than strict formulas to adhere to.

This study also provides an explicit understanding of the nature of the complexity embedded in a SHE intervention for children with DD. Findings show children's sleep problems need to be given enhanced legitimacy and demonstrate how this impacts on parent's help-seeking behaviours. Concordance is found with Robinson and Richdale's (2004) exploratory study which concluded that "many parents are poor at recognizing that a sleep problem exists. Treatment is frequently not sought even if the problem is recognized" (p.149) and attributed this to parents' 
knowledge of parenting and beliefs around sleep. Wiggs and Stores (1996) similarly reported reluctance from parents to seek help which they linked to stoicism and a belief they could carry on without professional help. Wider literature therefore, supports the premise that parents need to be encouraged to give more value and currency to children's sleep problems to ensure they receive appropriate help.

Findings also showed the need to give greater legitimacy to children's sleep problems to ensure adequate service provision. .This concurs with the Tired all the Time report (Family Fund, 2013) which reports that "sleep difficulties need to be given a higher priority by health, education and social care professionals and listed in the local offer (England)" (p.13). In reflecting on why sleep problems children with DD are poorly prioritised by organisations and policy makers, Beresford et al. (2012) point to the fact children with DD "are a small minority in a much larger population. Thus, there is a risk of them being overlooked by mainstream parenting activities at a local level" (p.271). Broad links can also be made with reports which have demonstrated how people with learning disabilities are a marginalised group who receive inequitable and inadequate healthcare (Atkinson et al., 2013; Department of Health, 2015; Disability Rights Commission, 2006; Emerson et al., 2012; Mencap, 2007). Therefore, the minority status of children with DD could explain why their sleep problems may go unnoticed by policy makers. It is also posited that the 'invisibility' of sleep problems to others outside the family home, may result in organisations placing less priority on the need for professional input. In contrast to other health issues (such as challenging behaviour or continence issues), sleep problems largely occur at bedtime or during the night, so their immediate impact is limited to the family. Reports that show how generic practitioners still need to treat parents of people with DD with greater respect and value their caring role (Department of Health, 2009; British Institute of Learning Disabilities (BILD), 2013) indicate how this explanation of "out of sight, out of mind" may be correct. 
This study makes explicit the need to customise SHE advice according to assessed need, rather than giving poorly informed or standardised advice, which implies a training need for sleep professionals. It is posited that if parents perceive advice is customised, they will feel motivated to follow it; positively impacting on implementation success. Parallels can be drawn with the personalisation agenda which shifts service provision away from a service led to a person centred ethos (Black et al., 2010; Davis and Gavidia-Payne, 2009; Mansell and BeadleBrown, 2004) and the principles of prudent healthcare (Bradley and Willson, 2014) which holds that patients should receive the minimum appropriate intervention to achieve health outcomes.

This study also makes explicit the nature of knowledge sharing within SHE. Employing experienced parent buddies to support implementation was largely supported by co-designers, but conflict around practitioner acceptability existed. This concurs with broader literature examining the role of lay health workers which highlights implementation issues such as role confusion and call for the adequate conceptualisation of this role (Glenton et al., 2013; Kennedy, Milton and Bundred, 2008). Furthermore, the knowledge sharing recommendation of psycho-education, is supported by (Beresford et al., 2016) who also found that increasing parental knowledge about sleep was instrumental improving children's sleep.

The complexity of how low health expectation can negatively impact on sleep problem recognition and active engagement with SHE was also demonstrated. This concurs with wider evidence which reflects how parents and practitioners often perceive sleep problems in children with DD to be inevitable and untreatable (Family Fund, 2013; McDougall, Kerr and Espie, 2005; Robinson and Richdale, 2004; Wiggs and Stores, 1996). Parallels can also be drawn with the 'diagnostic overshadowing' bias whereby a person's underlying health needs are overlooked and attributed to their learning disability (Mason, 2007; Mason and Scior, 2004). Furthermore, calls for practitioners to raise their health expectation of individuals with learning disabilities to 
ensure equitable care have also been demonstrated in recent reports (Department of Health, 2015; Disability Rights Commission, 2006; Mencap, 2007).

Finally, this study shows how implementation success is affected by sleep services adopting rationing and gaming strategies to manage scarce resources and meet performance targets. It is purported that such strategies can mask the true level of service need; an implication mirrored by Stores and Wiggs (2001) who suggest "services will not improve until a demand for better provision is felt"(p.6). Concordance is also found with policy guidance that calls for enhanced accessibility and clear referral routes to sleep services for children with DD (Family Fund, 2013; NHS England, 2015).

\section{Conclusion}

Study findings have highlighted a range of implications for policy, practice and research as follows:

\section{Policy:}

There is a need for:

- National sleep screening initiatives, media campaigns spreading positive messages about sleep, re-prioritisation and adequate resourcing of sleep service provision to foster a climate of positive health expectation and ensure children's sleep problems are legitimised.

- Enhanced understanding of how the customisation of SHE fits in with prudent healthcare and personalisation agendas.

- Greater awareness of the implications of rationing and gaming practices and commitment to improve parents' experiences of accessing professional sleep support.

\section{Practice:}


- Adequate sleep training for practitioners, so they can fully understand sleep problems, customise SHE and deliver psycho-education.

- More parental involvement in sleep assessment and decision making processes to facilitate knowledge exchange.

- To embed psycho-education into SHE interventions to facilitate knowledge exchange

- To champion parent support groups to ensure parents are supported with SHE implementation.

\section{Research:}

- Continued research into the experiences of families, to ensure children's sleep problems are afforded enhanced legitimacy and are current in the minds of policy makers.

- Research to conceptualise the paid parent role within SHE implementation to further develop the emerging discipline of lay helping within care.

- Piloting and feasibility work to ensure the SHE intervention can be carried out as intended, before a main evaluative study can be designed.

\section{Declaration of conflicting interests}

The Author(s) declare(s) that there is no conflict of interest. 


\title{
References
}

\author{
Author 1(...) DETAILS TO BE PROVIDED. \\ Armitage C J (2009) Is there utility in the transtheoretical model? British Journal of Health \\ Psychology 14(Pt 2): 195-210.
}

Astbury B and Leeuw FL (2010) Unpacking black boxes: Mechanisms and theory building in evaluation. American Journal of Evaluation 31(3): 363-381.

Atkinson D, Boulter P, Hebron, C, et al. (2013) The health equalities framework. Improving Health and Lives. Learning Disability Observatory.

Bandura A (1977) Self Efficacy: The Exercise of Control. New York: Freeman.

Bandura A (1997) Self-efficacy: Toward a unifying theory of behavioural change. Psychological Review 84: 191-215.

\begin{abstract}
Beresford B, Stuttard L, Clarke S, et al. (2012) Managing behaviour and sleep problems in disabled children: An investigation into the effectiveness and costs of parent-training interventions. DFE-RR204. Department for Education Research Report. London: Department for Education.
\end{abstract}




\begin{abstract}
Beresford B, Stuttard L, Clarke S, et al. (2016) Parent's experiences of psychoeducational sleep management interventions. A qualitative study of parents of children with neurodevelopmental disabilities. Clinical Practice in Pediatric Psychology 4(2): 164-175.
\end{abstract}

Bevan G and Hood C (2006) What's measured is what matters. Targets and gaming in the English public health care system. Public Administration 84 (3): 517-530.

Black C A, McConkey R, Roberts, P et al. (2010) Developing a person centred support service for families caring for children with severe learning disabilities in rural and urban areas. Journal of Intellectual and Developmental Disabilities 14 (2): 111-131.

Bonuck K and Grant R (2012) Sleep problems and early developmental delay: Implications for early intervention programs. Intellectual and Developmental disabilities 50(1):41-52.

Bradley P and Willson A (2014) Achieving prudent healthcare in NHS Wales. Cardiff: Public Health Wales.

Braun V and Clarke V (2006) Using thematic analysis in psychology. Qualitative Research in Psychology 3: 77-101.

British Institute of Learning Disabilities (2013) Summary Report: Is Healthcare Getting Better for People with Learning Disabilities. Birmingham: British Institute for Learning Disabilities.

Burnard P,Gill P, Stewart K et al. (2008) Analyzing and presenting qualitative data. British Dental Journal 204: 429-432.

Chen HT (2015).Practical Program Evaluation: Theory Driven Evaluation and the Integrated Evaluation Perspective. London: Sage. 
Creswell J (2007)Qualitative Inquiry and Research Design. Choosing Among Five Approaches. London: Sage.

Culham A and Nind M (2003) Deconstructing normalisation: clearing the way for inclusion. Journal of Intellectual and Developmental Disability 28(1): 65-78.

Davis K and Gavidia-Payne S (2009) The impact of child, family and professional support characteristics on the quality of life in families of young children with disabilities. Journal of Intellectual and Developmental Disabilities. 34(2): 153-162.

Davis H and Meltzer L (2007) Working in partnership through early support. Early Support. Department of Health.

deBlok C, Meijboom B, Luijkx K et al. (2012) The human dimension of modular care provision: Opportunities for personalization and customization. International Journal of Production Economics 142: 16-26.

Dempster R, Wildman B and Keating A (2013) The role of stigma in parental help-seeking for child behaviour problems. Journal of Clinical Child and Adolescent Psychiatry 42(1): 56-67.

Department of Health (2009) Valuing People Now. A New Three Year Strategy for People with Learning Disabilities. London: Department of Health.

Department of Health (2015) Transforming care for people with learning disabilities-Next Steps. London. Department of Health. 
Disability Rights Commission (2006) Equal Treatment: Closing the Gap. Stratford-Upon-Avon:
Disability Rights Commission.

Donetto S, Tsianakas V and Robert G (2014) Using Experience-based Co-design to improve the quality of healthcare: mapping where we are now and establishing future directions final report. London: King's College London.

Emerson E, Baines S, Allerton, L et al (2012) Health inequalities and people with learning disabilities in the UK. Improving Health and Lives. Learning Disability Observatory.

Family Fund (2013) Tired all the Time. The Impact of Sleep Difficulties on Families with Disabled Children. York: Family Fund.

Funnell SC and Rogers PJ (2011) Purposeful Program Theory: Effective Use of Theories of Change and Logic Models. San Francisco: Jossey-Bass.

Galland BC and Mitchell E A (2010) Helping children sleep. Archives of Disease in Childhood 95(10): 850-853.

Gilbert T (2004) Involving people with learning disabilities in research: issues and possibilities. Health and Social Care in the Community 12(4):298-308.

Glenton C, Colvin CJ, Carlsen B et al. (2013) Barriers and facilitators to the implementation of lay health worker programmes to improve access to maternal and child health: qualitative evidence synthesis. Cochrane Database of Systematic Reviews (10).

Jan JE, Owens J A, Weiss, MD et al. (2008) Sleep hygiene for children with neurodevelopmental disabilities. Pediatrics 122(6): 1343-1350. 
Janzen JA, Silvius, J, Jacobs, S et al. (2005) What is health expectation? Developing a pragmatic conceptual model from psychological theory. Health Expectation 9: 37-48.

Kennedy L.A, Milton B and Bundred P (2008) Lay food and health worker involvement in community nutrition and dietetics in England. Roles, responsibilities and relationships with professionals. Journal of Human Nutrition and Dietetics 21 (3): 210-224.

Locock L, Robert G, Boaz A et al (2014) Testing accelerated experience-based co-design: A qualitative study of using a national archive of patient experience narrative interviews to promote rapid patient-centred service improvement. Health Services and Delivery Research 2(4).

Malow B A, Adkins K W, Reynolds A et al. (2013) Parent-based sleep education for children with autism spectrum disorders. Journal of Autism and Developmental Disorders 44(1): 216228.

Mansell J and Beadle-Brown J (2004) Person-centred planning or person-centred action? A response to the commentaries. Journal of Applied Research in Intellectual Disabilities 17: 31-35.

Mason J (2007) The provision of psychotherapy to people with intellectual disabilities. An investigation into some of the relevant factors. Journal of Intellectual Disability Research 51, 3: 244-249.

Mason J and Scior I (2004) 'Diagnostic overshadowing' amongst clinicians working with people with intellectual disabilities in the UK. Journal of Applied Research in Intellectual Disabilities, 17, 2: 86-96. 
McDaid C and Sloper P (2009) Evidence of effectiveness of behavioural interventions to help parents manage sleep problems in young disabled children: A rapid review. York: Social Policy Research Unit.

\begin{abstract}
McDougall A, Kerr A M and Espie CA (2005) Sleep disturbance in children with rett syndrome: A qualitative investigation of the parental experience. Journal of Applied Research in Intellectual Disabilities 18: 201-215.
\end{abstract}

Medical Research Council (2000) Framework for the development and evaluation of RCTs for complex interventions to improve health. London: Medical Research Council.

Medical Research Council (2008) Developing and evaluating complex interventions: New guidance. London: Medical Research Council.

Mencap (2007) Death by Indifference. Following up the Treat Me Right! Report. London: Mencap.

Minvielle E, Waelli M, Sicotte C et al. (2014) Managing customization in health care. A framework derived from the service sector literature. Health Policy 177: 216-227.

National Health Service England (2015) Supporting people with and/or autism who display behaviour that challenges, including those with a mental health condition. Service model for commissioners of health and social care service. London: NHS England.

National Institute for Health and Care Excellence (NICE) (2013) Autism: The management and support of children and young people on the autism spectrum. (National clinical guideline no. 170). London: British Psychological Society and the Royal College of Psychiatrists. 
Nigg C R, Geller K S, Horwath CC et al. (2011) A research agenda to examine the efficacy and relevance of the transtheoretical model for physical activity behaviours. Psychology of Sport and Exercise 12(1): 7-12.

Pearpoint J, O’Brien J and Forest, M (1998) PATH. A Workbook for Planning Positive Possible Futures. Toronto: Inclusion Press.

Perkins D and Zimmerman M (1995) Empowerment theory, research and application. American Journal of Community Psychology 23(5):569-579.

Prochaska JO and DiClemente CC (1983) Stages and processes of self-change of smoking: Toward an integrative model of change. Journal of Consulting and Clinical Psychology 51(3): 390-395.

Prochaska JO and Velicer WF (1997) The transtheoretical model of health behaviour change. American Journal of Health Promotion 12(1): 38-48.

Reason P and Bradury H (2001) Introduction: Inquiry and participation in search of a world worthy of human aspiration. In: Reason $\mathrm{P}$ and Bradbury $\mathrm{H}$ (Eds) Handbook of action research . London: Sage, pp.1-14.

Robinson A M and Richdale A L (2004) Sleep problems in children with an intellectual disability: Parental perceptions of sleep problems, and views of treatment effectiveness. Child: Care, Health \& Development 30(2): 139-150.

Rodero E (2012) See it on a radio story. Sound effects and shots to evoked imagery and attention on audio fiction. Communication Research 39(4): 458-479.

Sanderson H and Lewis J (2012) A Practical Guide to Delivering Personalisation. Person Centred Practice in Health and Social Care. London: Jessica Kingsley. 
Stores G and Wiggs L (2001) Sleep disturbance: A serious, widespread, yet neglected problem in disorders of development. In : Stores $G$ and.Wiggs L (Eds) Sleep disturbance in children and adolescents with disorders of development: Its significance and management. New York, US: Cambridge University Press, pp.3-14.

Sutton J (2011) Promoting effective interventions for sleep problems. Nursing Children and Young People 23(8):14-8.

The King's Fund (2014) Experience based co-design toolkit. London: King's Fund.

Tietze A, Blankenburg, M, Hechler T et al. (2012) Sleep disturbances in children with multiple disabilities. Sleep Medicines Review 16(2): 117-127.

Tobiano G, Bucknall T, Marshall A et al. (2016) Patients' perceptions of participation in nursing care on medical wards. Scandinavian Journal of Caring Sciences 30: 260-270.

Vogel DL and Wade NG (2009) Stigma and help seeking. The British Psychological Society 22: 20-23.

Vriend J L, Corkum P V, Moon EC et al. (2011) Behavioral interventions for sleep problems in children with autism spectrum disorders: Current findings and future directions. Journal of Pediatric Psychology 36(9):1017-1029

Wiggs L and Stores G (1996) Sleep problems in children with severe intellectual disabilities: what help is being provided? Journal of Applied Research in Intellectual Disabilities $9: 159-164$.

Wolfensberger W and Tullman S (1982) A brief outline of the principle of normalization.

Rehabilitation Psychology 27(3): 131-145. 
[1] In all events the term sleep advice was used instead of SHE to ensure lay understanding. 
Table 1: Operational definition of developmental disabilities (DD). (This has been specifically developed for the purposes of this study and encompasses a variety of neurological conditions).

Conditions originating in the developmental period ( 0 -18 years) including specific learning difficulties, global developmental delay and disorders of psychological functioning such as Autistic Spectrum Disorder (ASD) (encompassing Autism and Asperger syndrome). Excludes children with a sole diagnosis of physical disabilities. 
Table 2: Six co-design study discussion themes.

1. Parents and practitioners have a shared understanding of what a sleep problem is.

2. Sleep services are well publicised and accessible for parents.

3. Parents and sleep practitioners develop a safe and supportive relationship.

4. Parents and sleep practitioners improve their understanding of the sleep problem.

5. Regularity and quality of child's sleep improves.

6. Quality of life improves for the family. 
Table 3: Parent participant characteristics

\begin{tabular}{|l|l|l|l|l|l|l|l|l|}
\hline $\begin{array}{l}\text { Parent } \\
\text { number }\end{array}$ & $\mathbf{1}$ & $\mathbf{2}$ & $\mathbf{3}$ & $\mathbf{4}$ & $\mathbf{5}$ & $\mathbf{6}$ & $\mathbf{7}$ & $\mathbf{8}$ \\
\hline Child's age & 9 & 14 & 7 & 12 & 7 & 8 & 16 & 14 \\
\hline $\begin{array}{l}\text { Child's } \\
\text { gender }\end{array}$ & Male & Male & Male & Male & Male & Male & Male & Male \\
\hline $\begin{array}{l}\text { Child's } \\
\text { diagnosis }\end{array}$ & $\begin{array}{l}\text { Learning } \\
\text { disabilities }\end{array}$ & ASD & ASD & ASD & ASD & ASD & ASD & ASD \\
\hline $\begin{array}{l}\text { Parent } \\
\text { participation } \\
\text { in co-design } \\
\text { event 1/ 2/ 3. }\end{array}$ & $1 \& 3$ & $1,2 \& 3$ & $1 \& 2$ & $1 \& 3$ & 1 & 1 & $1,2 \& 3$ & 3 \\
\hline
\end{tabular}


Table 4: Sleep practitioner participant characteristics

\begin{tabular}{|l|l|l|l|l|l|l|}
\hline $\begin{array}{l}\text { Practitioner } \\
\text { number }\end{array}$ & $\mathbf{1}$ & $\mathbf{2}$ & $\mathbf{3}$ & $\mathbf{4}$ & $\mathbf{5}$ & $\mathbf{6}$ \\
\hline $\begin{array}{l}\text { Practitioner } \\
\text { role. }\end{array}$ & FSO & SP & DO & DO & DO & DO \\
\hline Team type & SCT & VO & VO & VO & VO & VO \\
\hline $\begin{array}{l}\text { Co-design } \\
\text { event } \\
\text { participation: } \\
\text { 2/3. }\end{array}$ & $\mathbf{2 \& 3}$ & $\mathbf{2 \& 3}$ & $\mathbf{2}$ & $\mathbf{3}$ & $\mathbf{2}$ & $\mathbf{3}$ \\
\hline
\end{tabular}

KEY:

FSO- Family support officer

SP-Sleep practitioner

DO- Development officer

SCT- Social care team

VO- Voluntary organisation 
Table 5 SHE tool for children with DD

\begin{tabular}{|c|c|c|c|c|c|}
\hline 1.Sleep timing & 2.Bedtime routines & $\begin{array}{l}\text { 3.Behaviour } \\
\text { management }\end{array}$ & 4.Environment & 5.Physiological & $\begin{array}{l}\text { 6. Communication } \\
\text { adaptations }\end{array}$ \\
\hline $\begin{array}{l}\text { 1.1. Set consistent } \\
\text { bedtimes and wake } \\
\text { times (including holidays } \\
\text { and weekends) }\end{array}$ & 2.1.Set relaxing routine & $\begin{array}{l}\text { 3.1. Ensure bedroom is } \\
\text { not used a punishment } \\
\text { setting }\end{array}$ & $\begin{array}{l}\text { 4.1. Ensure quiet noise } \\
\text { levels at sleep times }\end{array}$ & $\begin{array}{l}\text { 5.1. Encourage healthy } \\
\text { diet, limit fat and sugar } \\
\text { intake. }\end{array}$ & $\begin{array}{l}\text { 6.1. Give clear } \\
\text { expectations, prompts } \\
\text { and cues. }\end{array}$ \\
\hline $\begin{array}{l}\text { 1.2. Set age appropriate } \\
\text { bedtimes }\end{array}$ & $\begin{array}{l}\text { 2.2. Discourage } \\
\text { television or blue light } \\
\text { emitting devices at } \\
\text { bedtime. (consider blue } \\
\text { light blocker sunglasses } \\
\text { if resistant) }\end{array}$ & $\begin{array}{l}\text { 3.2. Avoid soothing to } \\
\text { sleep with a bottle/breast } \\
\text { after 6-12 months old. } \\
\text { (\#care re: } \\
\text { weaning/feeding } \\
\text { difficulties) }\end{array}$ & $\begin{array}{l}\text { 4.2. Consider room } \\
\text { temperature } 16-20 \mathrm{c} \text {, } \\
\text { bedding and sleep } \\
\text { clothes to maintain } \\
\text { comfortable body } \\
\text { temperature }\end{array}$ & $\begin{array}{l}\text { 5.2. Encourage daily } \\
\text { exercise (but avoid this } \\
\text { late evening) }\end{array}$ & $\begin{array}{l}\text { 6.2. Incorporate } \\
\text { augmentative } \\
\text { communication } \\
\text { strategies }\end{array}$ \\
\hline $\begin{array}{l}\text { 1.3. Encourage age } \\
\text { appropriate daytime } \\
\text { napping }\end{array}$ & $\begin{array}{l}\text { 2.3.Consider alternative } \\
\text { therapies and relaxation } \\
\text { techniques }\end{array}$ & $\begin{array}{l}\text { 3.3. Incorporate rewards } \\
\text { which are meaningful to } \\
\text { the child. }\end{array}$ & $\begin{array}{l}\text { 4.3. Ensure a darkened } \\
\text { bedroom (black-out } \\
\text { blind) }\end{array}$ & $\begin{array}{l}\text { 5.3. Ensure child has } \\
\text { plenty of light in the day }\end{array}$ & $\begin{array}{l}\text { 6.3. Encourage routine } \\
\text { timing of all meals. }\end{array}$ \\
\hline $\begin{array}{l}1.4 \text { Avoid late afternoon } \\
\text { napping }\end{array}$ & 2.4. Limit bedtime rituals & $\begin{array}{l}\text { 3.4. Set and stick to } \\
\text { limits }\end{array}$ & $\begin{array}{l}\text { 4.4. Ensure bedroom has } \\
\text { a familiar layout and } \\
\text { calm decoration. }\end{array}$ & $\begin{array}{l}\text { 5.4. Avoid smoking and } \\
\text { alcohol }\end{array}$ & $\begin{array}{l}\text { 6.4. Consider visually } \\
\text { modelling routine using a } \\
\text { doll. }\end{array}$ \\
\hline \multirow[t]{6}{*}{$\begin{array}{l}1.5 \text { Avoid excessive time } \\
\text { in bed }\end{array}$} & $\begin{array}{l}2.5 \text { Ensure routine } \\
\text { activities are consistently } \\
\text { ordered and timed }\end{array}$ & $\begin{array}{l}\text { 3.5. Ensure child falls } \\
\text { asleep and sleeps alone } \\
\text { in own bed }\end{array}$ & $\begin{array}{l}\text { 4.5. Allow security object } \\
\text { to promote self-soothing }\end{array}$ & $\begin{array}{l}\text { 5.5. Light meals only near } \\
\text { bedtime. }\end{array}$ & $\begin{array}{l}\text { 6.5 Ensure bedroom is } \\
\text { only used for sleep and } \\
\text { calm activities. }\end{array}$ \\
\hline & $\begin{array}{l}\text { 2.6. Ensure routine is } \\
20-45 \text { minute duration }\end{array}$ & $\begin{array}{l}\text { 3.6. Put child to sleep } \\
\text { drowsy }\end{array}$ & $\begin{array}{l}\text { 4.6. Consider sensory } \\
\text { sensitivities of the child }\end{array}$ & 5.6. Limit caffeine intake & \\
\hline & & $\begin{array}{l}\text { 3.7.Give minimal } \\
\text { interactions during night } \\
\text { time feeds and night } \\
\text { awakenings }\end{array}$ & $\begin{array}{l}\text { 4.7. Ensure bed is } \\
\text { comfortable (consider } \\
\text { sleep systems) }\end{array}$ & $\begin{array}{l}\text { 5.7. Ensure child uses } \\
\text { toilet before bed }\end{array}$ & \\
\hline & & $\begin{array}{l}\text { 3.8. Encourage child to } \\
\text { think about } \\
\text { problems/plans before } \\
\text { going to bed }\end{array}$ & $\begin{array}{l}\text { 4.8. Remove or hide } \\
\text { stimulating toys in } \\
\text { bedroom }\end{array}$ & $\begin{array}{l}\text { 5.8. Encourage milk and } \\
\text { eat tryptophan/melatonin } \\
\text { rich foods with complex } \\
\text { carbohydrates at } \\
\text { suppertime. }\end{array}$ & \\
\hline & & & $\begin{array}{l}\text { 4.9. Use nightlight or red } \\
\text { modelling bulb if } \\
\text { preferred }\end{array}$ & $\begin{array}{l}\text { 5.9. Ensure child's } \\
\text { individual hydration needs } \\
\text { are met }\end{array}$ & \\
\hline & & & & $\begin{array}{l}\text { 5.10. Avoid blackcurrant } \\
\text { juice in the evenings }\end{array}$ & \\
\hline
\end{tabular}


Figure 1 Experience based co-design (King's Fund, 2014).
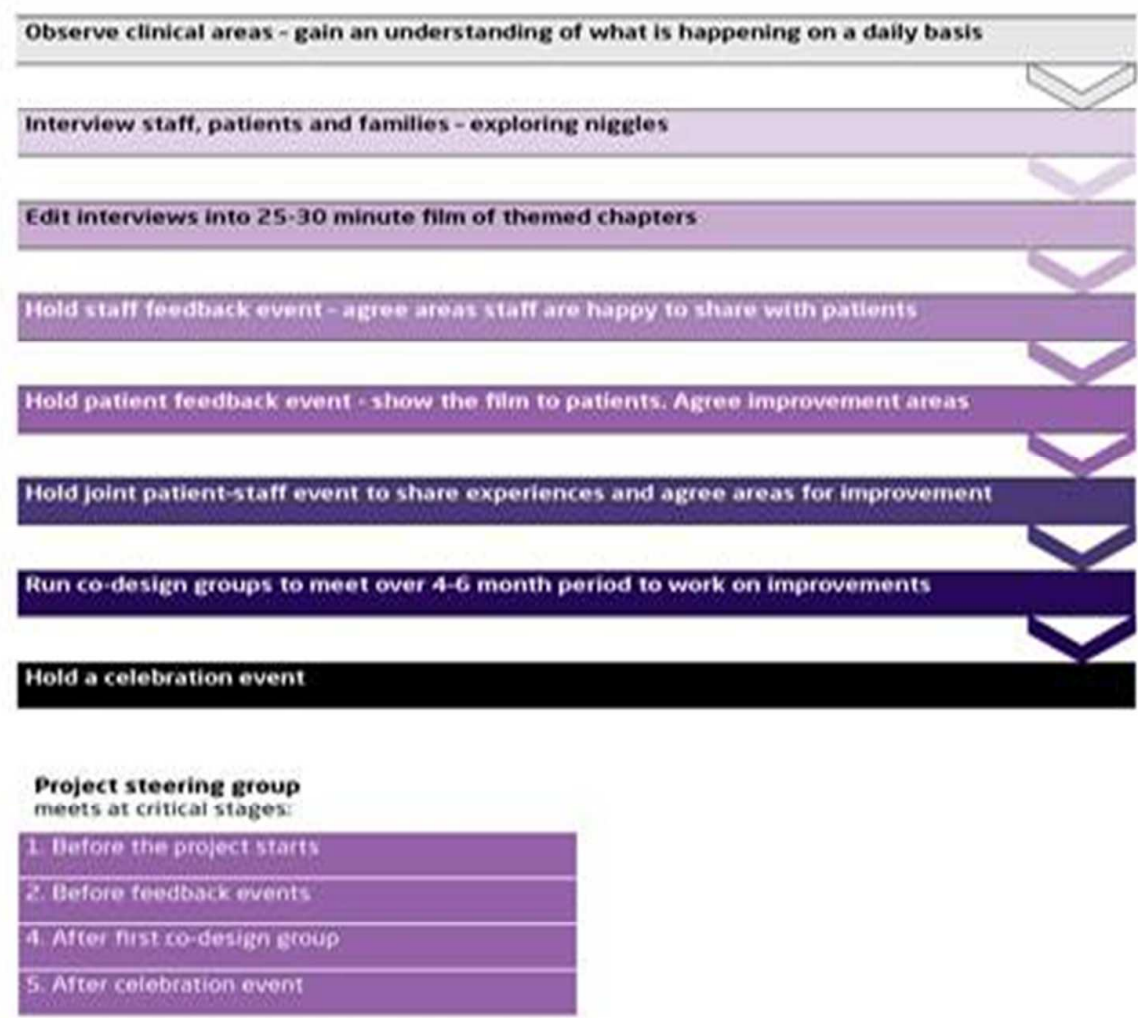
[Figure 2 to be inserted here] Overview of adapted co-design method.

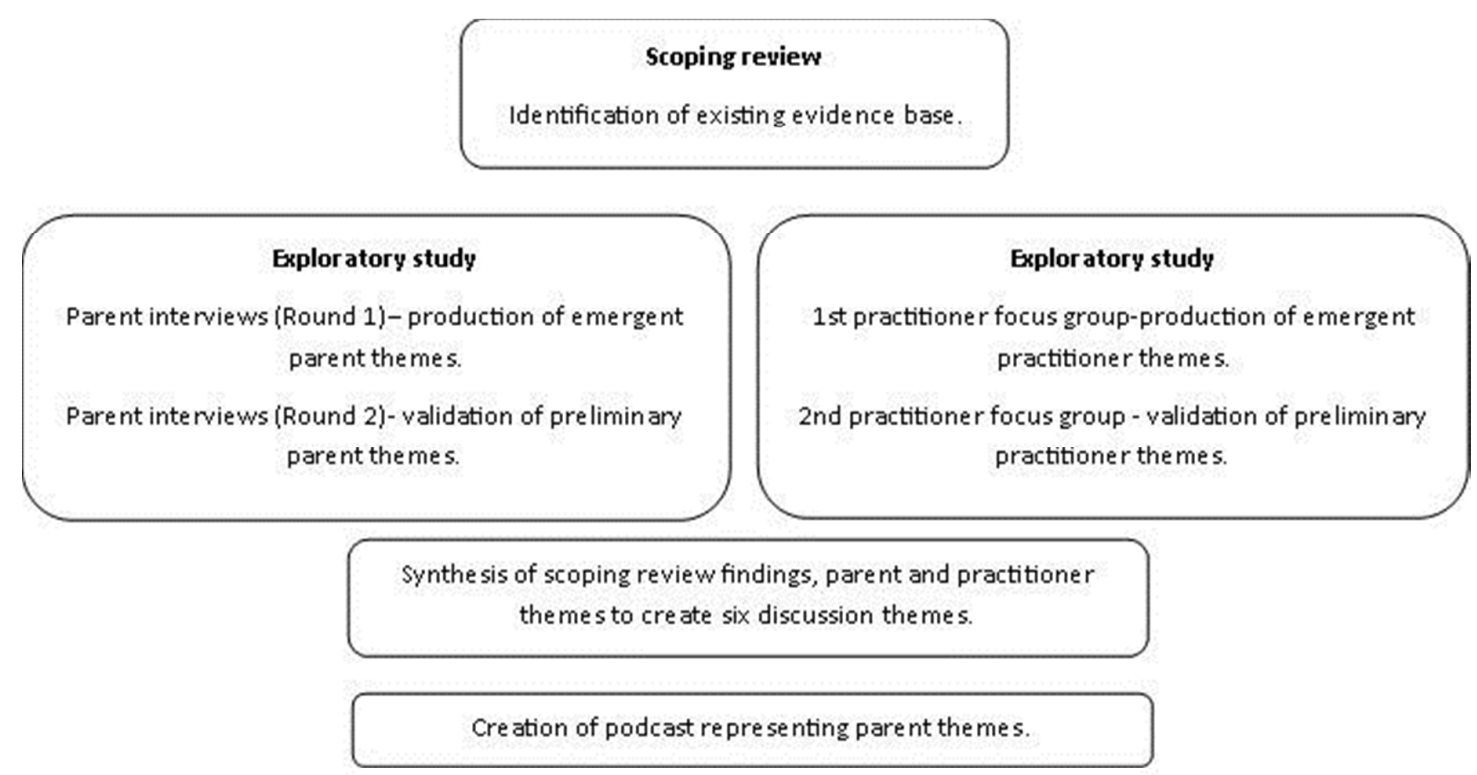

Discussion the mes and podcast pre sented to parents in co-de sign event 1 (parent only).

Discussion the mes and podcast pre sented to co-de signers in event 2 (joint parent/practitioner).

Continued de liberation of discussion the mes and co-de sign of preliminary SHE tool in event 3 (joint $p$ arent/practitioner). 


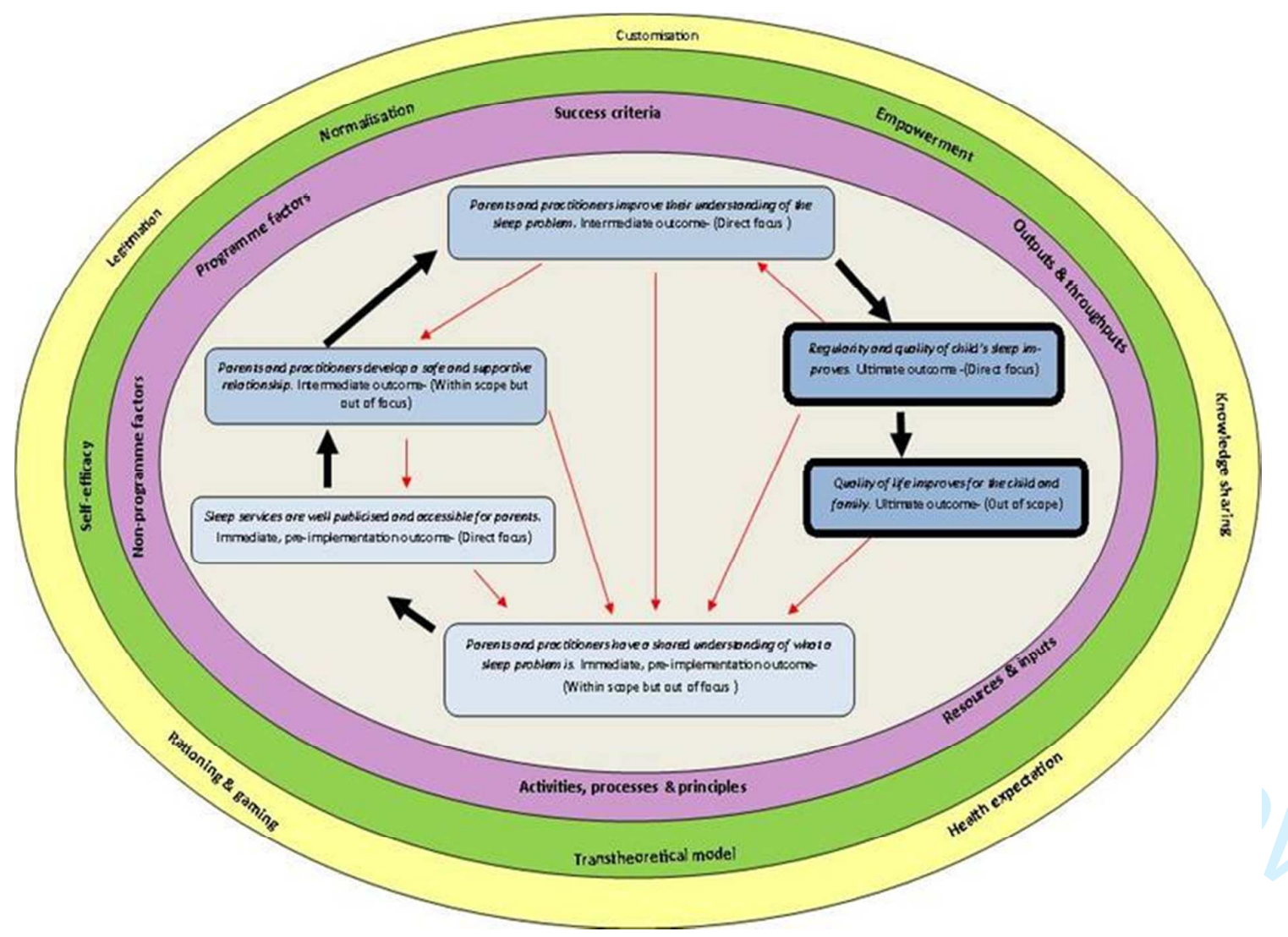

KEY:

Outcomes (theory of change)

Black arrows- intended

progression

Red arrows- unintended

movement

Theory of action

Mid-range theories

Novel analytical themes

Figure 3: SHE programme theory- outcomes chain logic model. Author 1 
